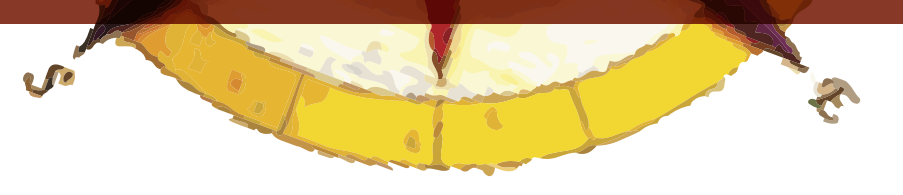

\title{
A GEOGRAFIA DO BRASIL: A CIÊNCIA E A DIDÁTICA DA CIÊNCIA NA EDUCAÇÃO BÁSICA
}

\author{
Leonardo Dirceu de Azambuja ${ }^{60}$
}

\section{RESUMEN}

La unidad científica y curricular de la Geografía y de la Geografía Escolar del Brasil es el objeto de reflexión del presente texto. Las referencias teóricas y metodológicas del análisis son explicadas y relacionadas con la interpretación geográfica de la formación socio espacial brasileña y, en esta perspectiva, las concepciones del território usado y de Región Concentrada son definidores del contenido-forma de la Geografía del Brasil. La proposición curricular a través de temas y de las metodologías cooperativas de enseñanza aprendizaje definen el contenidoforma de la Geografía Escolar de Brasil. Los temas producidos en la interacción de la ciencia con la realidad sociohistórica necesitan ser temas escolares asumiendo en su estudio la finalidad informativa,y principalmente formativa de la Educación Básica.

Palabras clave: Geografía del Brasil, Enseñanza de Geografía, Geografía de la educación básica.

\section{RESUMO}

A unidade científica e curricular da Geografia e da Geografia Escolar do Brasil é o objeto de reflexão do presente texto. As referências teóricas e metodológicas de análise são explicitadas e relacionadas com a interpretação geográfica da formação socioespacial brasileira e, nesta perspectiva, as concepções de território usado e de região concentrada são definidoras do conteúdo-forma da Geografia do Brasil. A proposição de organização curricular por meio de temas e das metodologias cooperativas de ensino-aprendizagem definem o conteúdo-forma da Geografia Escolar do Brasil. Os temas produzidos na interação da ciência com a realidade sócio-histórica precisam ser temas escolares assumindo no seu estudo a finalidade informativa e, principalmente, formativa da educação básica.

Palavras-chave: Geografia do Brasil, ensino de Geografia, Educação básica.

\begin{abstract}
The Scientific and curriculum unity of Geography and of Scholastic Geography of Brazil is the object of reflection of this text. The theoretical and methodological references of analysis are
\end{abstract}


explained and related to the interpretation of geographical socio-spatial formation. From this perspective, the conception of used territory and concentrated region are organizers of the content and form Geography of Brazil. The proposition of curriculum organization through the themes and the cooperative methodologies of teaching and learning define the content and the form the Scholastic Geography of Brazil. The themes produced by the interaction of science with the socio-historical reality need to be scholastic themes their study must assume the informative purposes, and especially formation of Basic Education.

Key words: Geography of the Brazil, Geography teaching, Basic education.

\section{INTRODUÇÃO}

Oportunizar espaço e tempo para a necessária relação das pessoas com o conhecimento é a finalidade primeira da escola. O conteúdo escolar constitui-se na relação do conhecimento científico e o conhecimento com origem no cotidiano dos alunos e também dos professores, ou seja, na relação conhecimento e realidade. Uma educação libertadora precisa assumir a qualidade de realizar com competência o acesso aos bens culturais e científicos da humanidade. A libertação, segundo Snyders (1988), está na superação da ignorância, do senso comum, da cultura primeira. Desenvolver a capacidade de leitura do mundo pela mediação conceitual das áreas do saber é essencial para a conquista de direitos.

A ciência na escola assume a finalidade pedagógica de formação e informação dos sujeitos. Para isso, evidencia-se a necessidade de unidade ou coerência do conteúdo-forma da ciência e do conteúdo-forma da didática da ciência. Não o saber pronto, pré-estabelecido e repassado ao aluno na forma definida pela pedagogia tradicional. E, sim, o saber científico universal, cujo processo de estudo e apropriação que acontece àa medida que os sujeitos (re) constroem o saber como um novo saber sobre a realidade sócio-histórica.

Os saberes acadêmicos são reconstruídos no processo de ensinar e de aprender, isto é, transpõem-se enquanto saber escolar dos professores e dos alunos. Pode-se dizer que é a forma escolar de produção e apropriação do saber. Não se trata de uma simplificação no sentido de diminuir a qualidade e a quantidade do conteúdo, mas, sim, de constituir a forma escolar como finalidade educativa, que não exclui a condição informativa do saber, porém é prioritariamente formativa dos sujeitos.

A mediação didática ou a relação dialógica na escola é estabelecida por meio da adoção do currículo. O currículo, ou a organização curricular, articula forma e conteúdo da prática social escolar. Num sentido mais abrangente, o currículo compreende todo o ambiente escolar, incluindo o conjunto arquitetônico que organiza os espaços físicos da escola, os componentes organizativos das relações pedagógicas e de gestão, os materiais didáticos e os instrumentos tecnológicos. Num sentido mais específico, compreende a referência aos conteúdos escolares, com ênfase nos aspectos cognitivos, informações e conceitos, incluindo necessariamente as dimensões do desenvolvimento de habilidades, valores e atitudes.

Vamos então refletir sobre essa unidade, científica, curricular e didática, da Geografia do Brasil nos ensinos fundamental e médio da educação básica. Esse é o objeto da reflexão que nos desafiamos desenvolver. Primeiro, vamos trabalhar algumas referências teóricas e metodológicas da Geografia e da análise geográfica do território brasileiro, a Geografia do Brasil. No momento seguinte, 
vamos explicitar alguns elementos para projetar as práticas escolares com base nas definições temáticas e nas metodologias cooperativas de ensino-aprendizagem, a Geografia Escolar do Brasil.

O presente texto tem origem na tese de doutoramento do autor defendida junto ao Programa de Pós-graduação em Geografia do Departamento de Geociências da Universidade Federal de Santa Catarina.

\section{A GEOGRAFIA DO BRASIL}

A análise geográfica. A análise geográfica é a interpretação da realidade social histórica, referenciando a dimensão socioespacial dessa realidade como produto e processo da dinâmica da natureza e da natureza socializada, humanizada. Por meio da análise geográfica, estaremos compreendendo a paisagem atual como resultado das transformações da natureza em sociedade, evidenciando ou desvendando a atualidade e movimento que constitui o espaço geográfico.

Desde as origens e a constituição, como ciência moderna, a Geografia estuda a natureza e a sociedade. No período clássico, o conhecimento geográfico produzia-se por meio da observação e da descrição das paisagens naturais e humanizadas, naturalizando o homem ou incluindo o como um dos elementos da paisagem. Agora, precisamos ir além da observação e descrição, sem desmerecer essas práticas, mas produzindo também a interpretação sobre o que os lugares representam como momentos da totalidade social. Os lugares ou os conjuntos de fatos geográficos existentes em cada espaço-tempo compõem a complexidade socioespacial a ser analisada e contextualizada.

A totalidade a ser produzida nesse processo terá como referência os fundamentos metodológicos, ou seja, a mediação pensamento e realidade, efetivada nos conceitos, ou na linguagem geográfica. Um problema ou um tema de estudo é, desde sua definição inicial, um problema teórico e metodológico. A realidade existe, não precisa ser inventada, porém, é por meio do pensamento que fazemos dela objetos disciplinares.

Assim, para termos objetos geográficos precisamos ter perguntas geográficas. Conforme Corrêa (1996), a pergunta geográfica inclui quatro definições: o recorte ou a definição temática, ou seja, o o quê; o recorte espacial, correspondendo à definição do onde, significando a localização e o até onde, a extensão; o quando das mudanças socioespaciais, e, ainda, o porquê, justificando a pertinência e o significado do tema ou do problema proposto. Recortar ou definir significa delimitar, identificar a parte que contém a totalidade a ser desvendada por meio do pensamento.

Para Santos (1985), a análise geográfica é a interpretação conjunta da estrutura, do processo, da função e da forma, e essa compreensão está sintonizada com a definição de espaço geográfico. Ao interpretar a realidade socioespacial como um conjunto indissociável, está reafirmando a ideia de que a Geografia não estuda os fatos ou elementos naturais e sociais isoladamente, mas, sim, o conjunto das relações que produzem ou são produzidas nesse meio. É preciso, portanto, compreender a estrutura, a organização espacial.

O espaço geográfico contém a paisagem, ou poderíamos dizer as formas, ou os sistemas de objetos. Mas as formas ou as paisagens são geográficas porque contém o processo, a formação ou a dimensão histórica, mas também porque são atuais, fazem parte dos lugares, da vida, da sociedade. A atualidade das formas inclui o sistema de ações, a forma e a função, esta, sempre no tempo presente. 
Os objetos existem antes, representam tempos passados da natureza e da sociedade, são produtos de sistemas de objetos e sistemas de ações anteriores, são agora trabalho morto, porém, ao seu tempo constituíram trabalho vivo. As ações atualizam e dão novo movimento aos objetos, significando à unidade trabalho morto e trabalho vivo enquanto a essência da reprodução social. Essa é a indissociabilidade dos objetos e das ações que constituem o espaço geográfico. E é por isso que as paisagens representam acumulação de tempos, pois são atualidade, mas são também rugosidades.

Nesse conteúdo-forma do espaço geográfico está a manifestação das desigualdades entre os lugares ou as regiões. As desigualdades socioespaciais são expressão dos diferentes estágios de desenvolvimento ou de como os homens, progressivamente, fazem a ruptura com o estágio natural da vida e constituem sociedades diferenciadas no tempo e no espaço. Compreender a origem, o processo e a atualidade dessas desigualdades é também contribuição da Geografia.

E nesse objeto de análise está a dimensão de segunda natureza que é interpretada, porém, esta foi e pode ainda incluir a dimensão de primeira natureza. As formas da natureza contribuem para as desigualdades dos lugares e/ou regiões. O assim chamado homem da Amazônia é diferente do sertanejo nordestino ou do gaúcho pampeano não somente pelas construções sócio-históricas, mas também porque se constituíram em condições naturais diferenciadas. A Geografia estuda a segunda natureza, porém, sempre com um pé na primeira natureza porque os sistemas de objetos são sociais e, ao mesmo tempo, naturais ou se constituíram com base em determinadas condições naturais.

Como então incluir na Geografia a análise das condições naturais? Os elementos da natureza, formações geológicas, formações geomorfológicas, climas, vegetação e fauna, rios, oceanos e mares, se consideradas em suas representações particulares não compreendem a complexidade geográfica. São objetos de outros campos de estudo das ciências naturais. Contudo, quando visualizadas as associações ou as combinações desses elementos, materializadas nos lugares, teremos então a integração da natureza como campo geográfico de estudo.

Na atualidade, o nível de especialização das ciências naturais define campos de estudos específicos: Geologia, Geomorfologia, Pedo-geomorfologia, Climatologia, Biologia, Hidrologia, Oceanografia etc. A Geografia trabalha interdisciplinarmente com essas áreas do conhecimento quando faz a relação geográfica com os ambientes naturais. A teoria geral dos sistemas é a referência para esses estudos por meio dos conceitos de bioma e ecossistema associados às Ciências Biológicas e à Ecologia e dos conceitos de geossistema e de domínio natural associados à Geografia e à Geomorfologia.

A periodização do território. Com essas concepções de objeto e método faz sentido propor uma periodização da formação social considerando o meio geográfico. Santos (1997) propõe três períodos: o primeiro período com o meio natural ou pré-técnico; outro período denominado como meio técnico ou técnico-científico; e o terceiro período o meio técnico-científico informacional.

No primeiro período em que prevalece o meio natural ou pré-técnico em que cada grupo humano vive em seu lugar e entorno imediato, sem relações significativas com o externo ou o mundo mais amplo. A caça, a pesca e a coleta são atividades que marcam a subsistência e a vivência na natureza. Os territórios da produção e do consumo são os mesmos e o grupo social também é o mesmo. Para Santos (1994), "[...] é o tempo do homem amigo e da natureza amiga" (p. 17).

Nesse período, a separação homem-natureza se apresenta ainda irrelevante. "As técnicas e o trabalho se casavam com as dádivas da natureza, com a qual se relacionavam sem outra mediação" 
(Santos, 1997, p. 188). Quer dizer, sem a mediação de instrumentos ou ferramentas de trabalho e sem um processo de trabalho que caracterizasse algum tipo de divisão técnica e/ou social a não ser aquelas ditadas pela própria natureza.

O período seguinte, denominado como meio técnico-cientifico, faz a associação da ciência e da técnica ao meio geográfico. O conhecimento torna-se força produtiva. Agora toda a natureza é passível de ser utilizada. A circulação entre os lugares até o nível mundial passa a ser parte da realidade. Nesse meio geográfico prevalece a lógica da concentração da economia e da sociedade, o que impõe mais investimentos em fixos, de modo que os fluxos tornam-se ainda mais densos.

O segundo período constitui o tempo histórico de formação da sociedade capitalista. Primeiro na fase mercantil do capitalismo, ainda em âmbito nacional, produção e circulação constituem vínculos estreitos com as possibilidades oferecidas pelas condições naturais. Já na fase de expansão ou de internacionalização do capitalismo, conhecida como período imperialista, há uma progressiva sobreposição dos meios artificiais sobre as condições oferecidas pela natureza. Ampliam-se os investimentos em infraestrutura em transportes, comunicações e energia, especializam-se os espaços ou as regiões de produção agrícola e industrial, e os espaços de consumo também se ampliam com o crescimento das cidades, com definições mais nítidas das hierarquias urbanas, das diferenças regionais, nacionais e internacionais.

Esse período é marcado pela transformação de valores-de-uso, os quais vão progressivamente assumindo a condição também de valores-de-troca, não apenas entre as pessoas ou grupos de um mesmo território, mas principalmente ampliando a circulação para outros lugares, ou para todos os lugares, redefinindo as formas e as funções do espaço geográfico.

O meio geográfico não tem mais o predomínio da natureza, e sim de fixos e fluxos comandados pelas relações sociais, pela organização capitalista da sociedade e sustentados por meios técnico-científicos, objetos artificiais que dão forma e conteúdo aos objetos e as ações. "[...] não é mais a natureza amiga, e o homem também não é mais seu amigo" (Santos, 1994, p. 19).

O terceiro período recebe denominações tais como, sociedade da informação, sociedade do conhecimento, período tecnológico, sociedade pós-industrial, dentre outras. A denominação incentivada por Milton Santos, meio técnico-científico-informacional, dá o sentido geográfico à interpretação dessa realidade contemporânea. Identifica uma continuidade do período anterior, técnico-científico, porém, agora aprofundando e qualificando a relação da ciência e da técnica. "Neste período, os objetos técnicos tendem a ser ao mesmo tempo técnicos e informacionais" (Santos, 1997, p. 190). O objeto contém a informação e seu uso também implica a apropriação de conhecimento. Os manuais, as bulas, as fórmulas, os rótulos, as mídias, a legislação sobre o espaço passam a ser parte dos processos produtivos, de circulação e de consumo.

O território se qualifica ao incorporar esses meios técnicos-cientificos-informacionais. O meio geográfico é equipado para cumprir com mais fluidez a finalidade reprodutiva do capital. Infovias, internet, cobertura de satélites meteorológicos e de telecomunicações fazem parte das próteses tecnológicas que se somam aos demais sistemas de engenharia existentes no espaço geográfico.

O meio geográfico passa a tencionar com mais presença o local e o global. Os objetos novos e também os novíssimos sob o comando de atores hegemônicos impõem sua velocidade e sua lógica 
aos processos socioespaciais, produzindo, de um lado, a acumulação da riqueza, e de outro, a escassez ou a miséria. Essa é a face perversa da globalização (Santos, 2000).

Constata-se uma unicidade técnica em escala planetária que aparentemente atende a toda a população e a todos os lugares, porém, atende com mais prioridade ou privilégio aos interesses do capital. São exemplos, o cartão de crédito utilizado em praticamente todo o mundo, a padronização de shopping centers em grandes e médias cidades, os padrões de qualidade e as normas sanitárias impostas pelos mercados e organismos internacionais para a produção agrícola e pecuária, plantas industriais localizadas onde são passíveis de vantagens comparativas pela existência de fontes de energia, matérias-primas, mão de obra, legislação, tributação, ou, ainda, os encaixes padronizados dos contêineres para viabilizar a circulação em portos, ferrovias ou estradas no mundo todo.

Essa unicidade do mundo não significa igualdade ou uniformidade, ao contrário, ampliam-se as diferenças entre os lugares e redefine-se a divisão territorial do trabalho com a especialização produtiva dos lugares. Os estados nacionais constituem-se em espaços nacionais da economia e da cultura internacionalizadas. "O meio técnico-científico-informacional é a cara geográfica da globalização." (Santos,1997, p. 191). O mesmo processo capitalista que faz a globalização promove também a fragmentação e a regionalização. A região não se constitui somente pela solidariedade ou identidade dos elementos geográficos localizados, mas também e principalmente é resultado da solidariedade das relações organizacionais capitalistas presente nos processos sociais, culturais e econômicos.

Nos espaços ou nas regiões periféricas, a modernização vem de fora e é seletiva, ou seja, apresenta efeitos diferenciados para as regiões e para as pessoas ou classes sociais. Numa região com maior densidade de meios técnicos-científicos-informacionais há mais fluidez, quer dizer, mais produtividade e velocidade de circulação e de consumo, exigindo mais especialização do trabalho e de intensificação de trocas regionais de produtos/mercadorias e de informações.

A fluidez do território é dada paradoxalmente pela existência de fixos, ou da fixidez (mais capital fixo, trabalho morto) significando infraestruturas, mas também o aparato de conhecimentos científicos e tecnológicos. Um exemplo dessa realidade pode ser o emprego da biotecnologia na produção agropecuária encurtando o tempo de produção de aves e suínos ou as plantações transgênicas que também alteram o ciclo natural dos cultivos agrícolas priorizando o lucro em detrimento da qualidade ambiental, ou, segundo alguns, sem o necessário atendimento ao princípio da precaução sócio-ambiental.

Muito mais do que em períodos anteriores, o espaço geográfico atual é produto e também produtor das relações sociais. Ampliam-se as relações internas e externas e os lugares tornam-se cada vez mais espaços localizados da fase atual da globalização Sobre o Brasil. Para a análise geográfica do Brasil, a referência é o território usado (Santos e Silveira, 2001), o que inclui a interpretação do processo de transformação de como o meio, antes natural, vai se constituindo em meio técnico-científico-informacional. É, também, interpretar as diferenças e as complexidades socioespaciais regionais como tempos diferenciados do processo de desenvolvimento das forças produtivas e das relações de produção, ou seja, dos diferentes estágios da divisão inter-regional do trabalho. Ainda, por meio da análise geográfica, interpretar os estágios de inserção do Brasil na divisão internacional do trabalho.

Nessa condição atual do território e com as referências acima esboçadas para análise e estudo do Brasil, ganha significado a definição de Região Concentrada, não como uma proposta de divisão 
regional, e sim, como proposta metodológica de interpretação da formação do território. Ao identificar o Brasil do Nordeste, do Centro-Oeste, da Amazônia e da Região Concentrada estaremos sintonizando a compreensão da formação socioespacial brasileira com as periodizações territoriais e com a ideia de um território em movimento, um território usado. Existe uma Região Concentrada porque existem outras regiões que não são Concentradas ou não detém essa condição, mas que estão incluídas numa mesma totalidade, num mesmo processo de desenvolvimento, que é desigual e combinado.

A análise geográfica com base na concepção de Região Concentrada inclui o pressuposto da diversidade espacial. A interpretação do Brasil está em compreender o estado-nação considerando a escala nacional, mas também, e principalmente, as realidades específicas identificadas nas escalas geográficas regional, subregional e local.

Desse modo, os estudos geográficos estarão identificados em recortes espaciais representativos de formações socioespaciais específicas, porém, como partes ou porções da formação socioespacial brasileira. Além dessas definições relacionadas com a periodização e a escala, os objetos geográficos são também temáticos. O método geográfico supõe duas definições básicas: a escala ou o recorte espacial de análise e a definição temática sobre a qual se constrói, pelo pensamento, a leitura da realidade.

As tematizações da Geografia. As grandes áreas temáticas da Geografia, herança do período Clássico dessa ciência, são as referências para essas tematizações. Continuamos estudando a agricultura, a indústria, o urbano, o comércio, os transportes e as comunicações, a Geografia Política e a Geopolítica, porém, procedendo a atualização e o detalhamento dessas temáticas quando necessário para o processo de produção do conhecimento.

Estudar o espaço agrário com base no conceito de sistemas agrícolas implica a interpretação do significado do uso mais ou menos intensivo dos fatores de produção, terra, capital e trabalho. Ou seja, da presença maior ou menor de ciência, tecnologia e informação na agricultura que acontece nas formações regionais ou subregionais de áreas já consolidadas ou em formações na fronteira do processo de ocupação capitalista do território brasileiro.

Estudar a urbanização brasileira inclui o processo de formação das cidades, as diferentes funções do urbano e as relações da cidade com o agrário, com a região e com os espaços extra-regionais, a rede urbana. Estudar o espaço urbano significa compreender a paisagem atual e as "rugosidades", o movimento e a atualidade, as formas e as funções das cidades de agora.

Estudar a industrialização brasileira significa compreender o processo ou as etapas de como o Brasil se torna uma sociedade urbano-industrial, com a definição de regiões e subregiões industrializadas. Mas é preciso estudar também os processos de produção, a composição orgânica do capital, significando o uso mais ou menos intensivo de ciência, tecnologia e informação e, ainda, os fatores de localização espacial das indústrias, relacionando-os aos diferentes ramos industriais.

A periodização e as diversidades do território marcam também o estudo sobre o comércio, os transportes e as comunicações. No primeiro período de formação ou de ocupação territorial do Brasil o meio natural poderia ser o obstáculo ou o elemento facilitador da circulação; no período seguinte o território incorpora meios técnicos de transportes e comunicações, porém, atendendo 
a diversidades locais e regionais; no terceiro período, a presença também diferenciada de meios técnicos-científicos-informacionais entre as diversas áreas do território acentuam as relações em rede ampliando a circulação das pessoas, dos produtos, das ideias e das ordens. A divisão territorial do trabalho é ainda mais demarcada pela existência de uma Região Concentrada, comandando a integração interna e externa do território brasileiro.

A população pode ser estudada como demografia, mas para a Geografia essa será uma temática que precisa ser interpretada integradamente com a economia política do território. Os temas para o estudo da população brasileira estarão relacionados como população agrícola ou agrária, população urbana, migrante, empregada ou desempregada, analfabeta ou alfabetizada, inserida ou não no consumo de bens duráveis e não duráveis, de bens culturais e de informações, dos serviços de saúde e de educação, ou, ainda, do ponto de vista das relações étnico-raciais.

A Geografia Política e a Geopolítica constituem campos de estudo com aproximações de significados. Identificar, localizar e interpretar a distribuição dos estados na superfície terrestre pode ser o objeto de estudo da primeira. Já a Geopolítica corresponde à compreensão das relações espaço e poder, ou, então, de como as definições políticas da sociedade materializam-se no território. Daí que a incorporação de ciência, tecnologia e informação oportunizam novos valores estratégicos ao espaço geográfico com novas racionalidades e significados para os territórios e suas fronteiras. Estudar as mudanças no mapa político e das políticas públicas do Brasil e/ou a inserção internacional do Brasil serão campos de estudo dessas especificidades temáticas.

Os conteúdos disciplinares da Geografia Escolar terão sempre relação com essas grandes áreas temáticas da ciência geográfica. Porém, nessa transposição de temas geográficos para temas escolares, também o foco será espacial. Ou seja, as duas alternativas podem ser evidenciadas nessas definições e sem a exclusão de uma ou outra dessas dimensões. O temático será, também, espacial e vice-versa. Os temas de estudo serão aproximações ou atualizações elaboradas em conformidade com as especificidades da comunidade escolar e da realidade. Vamos então refletir sobre essa prática.

\section{A GEOGRAFIA ESCOLAR DO BRASIL}

Desenvolver a mediação didática do conhecimento científico com o conhecimento cotidiano ou com a realidade significa elaborar a forma escolar do conhecimento. Para isso, a nossa aposta inclui a ideia do estudo de temas e a realização das práticas de ensino-aprendizagem por meio de metodologias de ensino cooperativas.

Sobre o tema. Para a Geografia, a definição do tema significa estabelecer a periodização e os respectivos recortes espaciais e temáticos, ou seja, estabelecer e delimitar a parte da realidade que será objeto da análise geográfica. Para a Geografia Escolar, é necessário fazer a contextualização desse objeto geográfico, elaborando um sentido histórico-social para o aluno. O tema da Geografia será, então, convertido em tema disciplinar escolar.

O tema é a parte ou a definição do objeto de estudo. Estudar o Brasil real, contemplando todas as escalas de análise e todas as temáticas oferecidas por essa realidade, é um desafio inesgotável ou permanente. Os temas terão referências na ciência geográfica, mas também nos contextos conjunturais do país, das regiões, subregiões e localidades. 
É necessário encontrar uma entrada para o estudo do espaço geográfico. Essa escolha será motivada pelo momento vivido e/ou pelo acesso às informações relacionadas ao contexto vivenciado pelo aluno ou na atualidade. O tema será a forma de aproximação da universalidade da ciência com a particularidade da vida do aluno, do professor e dos demais sujeitos da comunidade escolar, oportunizando maior reconhecimento pedagógico para a disciplina.

A escolha dos temas de estudo é parte do planejamento das práticas de ensino-aprendizagem. Eles precisam ser objetos de definição com a participação dos sujeitos que fazem a educação escolar. Os temas surgem das diferentes realidades e do saber conceitual, informativo e metodológico da Geografia. Eles podem estar referidos com situações socioespaciais nas quais os alunos e os professores percebam relações, significados, identidades e pertencimentos, e isso sem deixar de aceitar e compreender as dimensões multiescalares da realidade.

Metodologias cooperativas. As metodologias são cooperativas porque instigam o coletivo ou a cooperação entre os sujeitos da comunidade escolar, o diálogo entre as disciplinas e/ou áreas do conhecimento, criam necessidades para o uso de diferentes fontes ou meios didáticos e das diferentes linguagens incluindo sons, textos e imagens. As referências nesse sentido são as metodologias já identificadas no campo da didática: projeto de trabalho, unidade temática, situação de estudo e estudo do meio. Vejamos como pode ser efetivado esse processo numa determinada realidade escolar.

No coletivo da escola define-se um tema amplo ou geral em torno do qual se desenvolvem algumas atividades. Desse tema geral as turmas de alunos e/ou áreas do conhecimento podem vislumbrar possíveis desdobramentos em temas mais específicos ou subtemas sobre os quais também podem acontecer atividades geradoras ainda comuns a todos os sujeitos envolvidos. Serão palestras, filmes, observações de campo e/ou ações junto à comunidade, uma gincana, uma campanha socioambiental, por exemplo.

Os temas disciplinares podem, então, ser definidos considerando a trajetória da comunidade escolar. Pode ser uma reprodução dos temas mais gerais ou uma (re)tematização com base nas referências colocadas pelos objetos disciplinares de estudo. Para exemplificar: a escola pode estar trabalhando com a temática geral dos resíduos sólidos (lixo) e, na disciplina de Geografia, a partir das situações evidenciadas, pode ser trabalhado o tema da indústria ou sobre o consumo industrial. Esse momento de definição do tema específico da disciplina precisa ser entendido como um ponto de chegada e um novo ponto de partida uma vez que se desdobra em novos estudos. É um novo tema, é a parte que contém a totalidade a ser desvendada no processo de estudo.

Esse será então o momento das disciplinas e/ou da interdisciplinaridade a ser desenvolvido nas formas das metodologias cooperativas. Para a Geografia, esse desafio é instigador, e é possível que seja realizado. $\mathrm{O}$ ponto de partida precisará ser um momento de problematização das práticas sociais relacionadas com o tema, interagindo com o conhecimento geográfico ou evidenciando as necessidades interdisciplinares.

Assim, o tema escolhido se reconstrói como problema ou objeto de estudo da Geografia Escolar por meio da realização de atividades problematizadoras para as quais os processos mais amplos já desenvolvidos na escola e as informações e recursos didáticos relacionados com a Geografia e com o contexto escolar e/ou a conjuntura socioespacial serão elementos essenciais. É também o momento de resgate do conhecimento elaborado no cotidiano dos alunos, o qual estará questionando e será questionado à medida que se coloca no contraponto com as novas informações. 
As atividades problematizadoras serão aquelas em que alunos e professores explicitam suas perguntas, adentram ao tema, assumem o tema como um problema também seu, constroem necessidades de conhecer, de saber mais. Serão aulas de perguntas e não de respostas, de construção do problema, de reconstrução ou significação social e histórica do conteúdo. Poderá ser o momento do texto-pretexto, ou seja, do uso de um texto literário, uma letra de música, uma notícia de jornal, uma peça publicitária, uma ou mais fotos, enfim, recursos didáticos que poderão auxiliar esse debate inicial e problematizador.

A instrumentalização, ou seja, a apropriação refletida de novas informações e de (re)significação das informações já conhecidas pelos sujeitos, é a etapa subsequente do processo. Nesse momento, por meio de estudos bibliográficos, trabalhos de campo, palestras e aulas expositivas e, também, por meio das tecnologias de informação e comunicação, sempre com a mediação docente, efetiva-se a coleta ou a pesquisa de dados e/ou informações. Esses dados e/ou informações transformam-se em conhecimento escolar. O conhecimento é a informação refletida, porque foi pensada e contextualizada.

Os estudos bibliográficos terão como fontes impressas ou virtuais os próprios livros didáticos, outros livros, enciclopédias, jornais, revistas, atlas escolares. Os alunos precisarão ser orientados para esse momento de leitura e registro das informações (não cópia) existentes em textos, mapas, gráficos e tabelas. Esse procedimento torna o livro didático um das fontes de estudo, relativizando a função de manual didático definida na pedagogia tradicional.

O trabalho de campo precisará ser organizado também como um momento de pesquisa com base em questionamentos elaborados sobre o tema em estudo. $\mathrm{O}$ aluno vai a campo com os olhos e a mente do estudante para observar paisagens e espaços geográficos, entrevistar pessoas e coletar dados a partir de suas referências conceituais e de vida.

O planejamento de um trabalho de campo constará da elaboração dos objetivos e do conteúdo a ser buscado, da organização de materiais e da elaboração prévia de roteiros, da organização das formas de registro e sistematização dos resultados, incluindo nessa finalização as interações ou as contribuições para o estudo do conteúdo em pauta.

A aula expositiva, a palestra, o audiovisual (filme, documentário) também poderão ser momentos de estudo e de contextualização dos conteúdos. Serão aulas planejadas na rotina e para além da rotina cotidiana da sala de aula, mas integradas ao processo: é necessário motivar os alunos para a participação e para as elaborações posteriores, valorizando os conhecimentos trabalhados na relação com os objetivos do estudo.

Com a internet, o hipertexto virtual será mais uma fonte de pesquisa para ampliar o universo de informações articuladas por diferentes linguagens ou mídias. As orientações e mediações dos professores incluirão a seleção dessas fontes, considerando o que será pesquisado e como se dará o registro e o uso das informações. A informática poderá ser um instrumento muito útil para a sistematização e exposição dos trabalhos escolares.

O processo didático completa-se com a etapa da produção ou de elaborações das sínteses, da dimensão de totalidade a que se conseguiu atingir no processo de estudo. Esse momento materializa-se nos textos ou hipertextos dos alunos, nas formas de desenhos, croquis, maquetes, mapas, gráfi- 
cos, tabelas, quadros-murais, exposições, expressões literárias e artísticas (teatro, música, poesia) e ações práticas na comunidade. Serão os trabalhos de sistematização e exposição dos resultados dos estudos realizados.

\section{CONSIDERAÇÕES FINAIS}

O debate teórico e metodológico da Geografia e do seu ensino precisa ser permanente e neste texto objetivamos contribuir nessa perspectiva. Escrevemos sobre o objeto e o método da ciência e da interpretação geográfica do Brasil, o conteúdo-forma da Geografia. E também escrevemos sobre o ensino-aprendizagem da Geografia do Brasil, o conteúdo-forma da Geografia Escolar.

Compreendemos que a Geografia precisa ir para além da descrição, incluindo a explicação ou a interpretação dos lugares. Entendemos, também, que os lugares existem para além de sua materialidade (objetos) para serem também sociedade (ações). Daí a necessidade em assumir como objeto de estudo da Geografia o espaço geográfico, esse conjunto indissociável de sistemas de objetos e sistemas de ações.

Vimos que esses pressupostos teóricos e metodológicos para a análise geográfica da formação socioespacial brasileira são coerentes com a forma de periodização do território e com a concepção de território usado e de Região Concentrada.

Sobre a organização curricular e o desenvolvimento das práticas de ensino-aprendizagem de Geografia explicitamos a perspectiva da definição de temas originados na universalidade da ciência, mas também no processo de planejamento do ensino como prática singular em cada escola e/ou turma de alunos.

E essas definições temáticas trabalhadas por meio das proposições, que denominamos como metodologias cooperativas, serão definidoras do conteúdo-forma escolar da Geografia do Brasil. Alunos e professores de cada escola estarão então desafiados à elaboração de sínteses do conhecimento escolar atendendo à finalidade informativa e formativa da educação.

\section{BIBLIOGRAFIA}

Azambuja, L. D. (2010) A Geografia do Brasil na educação básica. 206 p. (Tese de Doutorado em). Florianópolis, Universidade Federal de Santa Catarina.

. Metodologias cooperativas para ensinar e aprender Geografia. In: Callai, H. C. (Org.) (2011). Educação geográfica: reflexões e práticas. Ijuí: Editora Unijuí, 185-210.

Corrêa, R. L. (1996). Elaboração de projeto de pesquisa: um guia prático para os geógrafos. In: Geosul. Florianópolis: UFSC, 11 (21/22), 169-172.

Santos, M. (1985). Espaço e método. São Paulo: Nobel.

Globalização e redescoberta da natureza. In: SANTOS, Milton. (1994). Técnica, espaço e tempo: globalização e meio técnico-científico-informacional. São Paulo: Hucitec, 15-28. 
. (1997). A natureza do espaço: técnica e tempo, razão e emoção. São Paulo: Hucitec.

(2000). Por uma outra globalização: do pensamento único à consciência universal. Rio de Janeiro: Record.

Santos, M.; Silveira, M. L. (2001). Brasil: território e sociedade no início do século XXI. Rio de Janeiro: Record.

Snyders, G. (1988). A alegria na escola. São Paulo: Manole.

Artículo recibido 20 - 09 - 11. Aprobado 25 - $11-11$. 